\title{
Maternidad indignada: reflexiones sobre el activismo de las madres negras y el uso de las emociones en investigación activista
}

\author{
Luciane de Oliveira Rocha \\ University of Manchester y RAIAR \\ lucianeorocha@utexas.edu
}

RESUMEN

Este artículo explora los usos de la emoción en la investigación activista inspirado en la acción directa de madres negras contra la violencia racial en comunidades afrodiaspóricas. La indignación que sienten por la ausencia de una persona en casa a causa de la violencia las capacita para expresar las agresiones que permean a sus familias y las comunidades negras por la violencia directa, la opresión y el terror en sus vidas debido a la intersección de raza, género o espacio. La investigación etnográfica realizada en colaboración con esas madres desde 2010 apunta a la necesidad de nuevos enfoques de la antropología, con el fin de comprender la complejidad de su lucha. Por lo tanto, este artículo defiende una antropología indignada, una antropología que reconoce las emociones como una expresión de una persona o grupo de personas en oposición a una estructura injusta de poder, y reconoce los mecanismos por los cuales la persona o grupo trata con la emoción como una narrativa de resistencia y fuente de lucha colectiva. Este enfoque incluye una perspectiva feminista negra como un puente entre los métodos de los estudios de la diáspora africana y la antropología de las emociones. Planteo que el reconocimiento de la emoción como dato antropológico en la investigación activista y el valor de los sentimientos como una metodología de personas oprimidas pueden mejorar el análisis, la escritura y crear nuevas fuentes de visión y posibilidades politicas.

Palabras clave: maternidad negra, genocidio, investigación activista, emociones, indignación. 


\title{
Outraged Mothering: Reflections about Black Mothers Activism and the Uses of Emotions in Activist Research
}

\author{
ABSTRACT
}

This article explores the uses of emotion in activist research inspired by the direct action of Black mothers against racial violence in Afro Diasporic communities. The outrage they feel due to the missing body at home taken by violence, empower them to voice the aggressions that permeate their families and the black communities by direct violence, oppression and terror in their lives through the intersection of race, gender, space. Ethnographic research in collaboration with these mothers since 2010 points to the necessity of new approaches to Anthropology in order to understand the complexity of their luta [struggle]. Therefore, this article advocates for an Outraged Anthropology, an anthropology that recognizes emotions as an expression of a person or group of people's position in an unjust structure of power; and recognizes the mechanisms in which the person/group deals with emotion as a narrative of resistance and source of collective struggle. This approach includes a Blackfeminist perspective as a bridge between African Diaspora Studies'methodologies and the Anthropology of Emotions. I argue that the recognition of emotion as anthropological data in activist research, and the valorization of feelings as methodology of oppressed people can enhance analysis, writing and creates new sources of insight and political possibilities.

Keywords: black maternity, genocide, activist research, emotions, affront.

\section{Maternidade Ultrajada: Reflexões sobre o ativismo de mães negras e o uso de emoções na Pesquisa Ativista}

\author{
RESUMO
}

Este artigo explora os usos da emoção na pesquisa ativista inspirada na ação direta de mães negras contra a violência racial em comunidades afrodiaspóricas. A indignação que sentem em devido 
à ausência de uma pessoa em casa, tomada pela violência, as capacita a expressar as agressões que permeiam suas famílias e as comunidades negras pela violência direta, opressão e terror em suas vidas através da interseção de raça, gênero, espaço. A pesquisa etnográfica em colaboração com essas mães, desde 2010, aponta para a necessidade de novas abordagens da Antropologia, a fim de compreender a complexidade de sua luta. Portanto, este artigo defende uma Antropologia Ultrajada, uma antropologia que reconhece as emoções como uma expressão de uma pessoa ou grupo de pessoas em oposição a uma estrutura injusta de poder; e reconhece os mecanismos pelos quais a pessoa ou grupo lida com a emoção como uma narrativa de resistência e fonte de luta coletiva. Esta abordagem inclui uma perspectiva feminista negra como uma ponte entre os métodos dos Estudos da Diáspora Africana e a Antropologia das Emoções. Defendo que o reconhecimento da emoção como dados antropológicos na pesquisa ativista e o valor dos sentimentos como uma metodologia de pessoas oprimidas podem melhorar a análise, a escrita e criar novas fontes de insight e possibilidades politicas.

Palavras-chave: maternidade negra, genocídio, pesquisa ativista, emoções, ultraje. 
Es imposible pensar en los hombres y las mujeres negros de la diáspora africana sobreviviendo a los continuos actos de violencia estructural y gratuita sin tener en cuenta la contribución social, cultural y emocional de las mujeres negras. Desde la resistencia a la esclavitud en el Brasil y las estrategias contra el linchamiento en los Estados Unidos hasta las luchas actuales por trascender el genocidio antinegro en diversos países de la diáspora africana, es imposible negar la importancia del pensamiento y la participación de las mujeres negras en las estrategias políticas para garantizar la vida de sus seres queridos y de otras personas en sus comunidades. Recordamos el importante papel desempeñado por Harriet Tubman, nacida en los Estados Unidos y esclavizada: ella escapó y posteriormente rescató a cerca de setenta personas esclavizadas utilizando la red de activistas antiesclavistas y refugios conocidos como ferrocarril subterráneo (Lowry, 2008). En Brasil, recordamos a Teresa de Benguela, que se convirtió en la reina del Quilombo de Quariterê. Bajo su liderazgo, las comunidades negras e indígenas resistieron la esclavitud durante dos décadas (Geledes, 2014). En la actualidad vemos a mujeres negras en Brasil $\mathrm{y}$ en los Estados Unidos que salen al frente de sus comunidades para denunciar la violencia del Estado contra jóvenes negros y negras. Por lo general, ellas son las que expresan el dolor de su luto y claman por justicia para la muerte de sus hijos e hijas, y para los hijos de la comunidad. Tales actos tienen conexión directa con su posición como madres. En este ensayo investigo las estrategias políticas de cuatro mujeres negras de Brasil y de los Estados Unidos, que tienen en común no solo el asesinato de una hija o hijo sino que también comparten fuerza, rabia, indignación, y la capacidad y el tremendo coraje de denunciar el terror que afecta la vida de la población negra de la cual forman parte.

Este artículo está dividido en tres secciones. En primer lugar, presento el contexto de muerte prematura y evitable en estos dos países de la diáspora africana. Luego, establezco una relación entre el uso de las emociones como estrategia política en el activismo de las cuatro madres de víctimas de violencia. Por último, reflexiono sobre cómo el uso de las emociones puede enriquecer la antropología activista. Para el análisis de los datos etnográficos, autobiografías y los informes periódicos, en este documento implemento el concepto de lucha indignada para analizar la lucha de estas madres contra la violencia a sus hijos e hijas, cuyas características me llevan a proponer una antropología de la indignación. 


\section{MATERNIDAD EN GEOGRAFÍAS DE MUERTE}

La exposición de la población negra a situaciones cotidianas de violencia indica una interacción de aspectos estructurales como racismo, pobreza, y discriminación de género, cuyas causas socioeconómicas, culturales e ideológicas surgen a partir de la subintegración de los negros en las sociedades. Esta interacción produce lo que algunos autores definen como la geografía de muerte, es decir, «la correlación entre la vulnerabilidad a la muerte y nuevas formaciones raciales, ya que se cruzan con la clase social, la edad, el género y el lugar» (Vargas y Alves, 2009, p. 1). Como han demostrado los autores, en las geografías de la muerte, los jóvenes negros son los principales objetivos de la violencia debido a la vulnerabilidad causada por la intersección de diversas opresiones en su vida.

Situaciones similares de discriminación racial, asesinato, encarcelamiento y terror se producen en Brasil y en los Estados Unidos. En ambos países los homicidios tienen raza y lugar. Datos recientes muestran que los jóvenes negros que viven en zonas pobres corren un gran riesgo de ser víctimas de homicidio. La intersección de características de raza, género, clase, lugar, y de una ideología racista en la sociedad que se manifiesta en el sistema punitivo, hace de los jóvenes negros los principales objetivos de la violencia. En los Estados Unidos, las probabilidades de morir a causa de homicidios por armas de fuego son mucho mayores para las personas que viven en las ciudades. Veinte por ciento de todos los homicidios por arma de fuego en Estados Unidos ocurren en las veinticinco mayores ciudades del país, aunque contengan poco más de una décima parte de la población de Estados Unidos. Los datos de los Centros de Control y Prevención de Enfermedades muestran que, de los 12979 homicidios por arma de fuego en 2015 , el $81 \%$ ocurrió en áreas urbanas. Las personas negras tienen en promedio ocho veces más probabilidades de morir por armas de fuego que las blancas. En 2014, Michael Brown, un adolescente negro desarmado, fue muerto a tiros por Darren Wilson, un policía blanco en Ferguson, Missouri' ${ }^{1}$ En Brasil, podemos decir que hay por lo menos trece «Michael Brown» todos los días. Los datos del mapa de la violencia en 2016 muestran que la victimización negra en el país subió del $71,7 \%$ en 2003 al $158,9 \%$ en 2014 . Esto quiere decir que morían, proporcionalmente, el 158,9\% más personas negras que blancas (Waiselfisz, 2016). Esta publicación también constata que, de los casi 45000 homicidios en 2014

La muerte provocó protestas que sacudieron la zona durante semanas. El 24 de noviembre, el fiscal de San Luis anunció que un jurado decidió no acusar al señor Wilson. El anuncio dio inicio a otra ola de protestas. 
en Brasil, $60 \%$ eran jóvenes. De ellos, el 70,5\% de las víctimas eran negros y el 94,4\% eran varones (Waiselfisz, 2016). De acuerdo con el Foro Brasileño de Seguridad Pública, la policía brasileña mató a 5012 personas solo en 2017 (Velasco et al., 2017). El Atlas de la Violencia 2018 muestra que se cometieron 62517 homicidios en el país en 2016 (Cerqueira et al., 2018). Aunque el Estado no es materialmente responsable de toda la violencia que ocurre, las prácticas estatales se combinan con la masculinidad patriarcal ${ }^{2}$ para facilitar la reproducción de la violencia de hombres negros contra hombres negros.

Ideologías racistas en ambos países hacen que los jóvenes negros sean estereotipados como enemigos y habitualmente tratados como sospechosos, independientemente de su participación en la delincuencia. Las investigadoras Silvia Ramos y Leonarda Massumeci (2005) muestran que en Río de Janeiro la Policía y la sociedad caracterizan a los jóvenes negros predominantemente como sospechosos. Cuando las investigadoras pidieron hacer un dibujo para representar las características de las personas que la Policía por lo general tiende a detener en la calle, jóvenes de diferentes orígenes dibujaron imágenes con las mismas características: un hombre negro, con pantalones cortos y gorras, y una cadena de oro alrededor del cuello. Es el estereotipo de los jóvenes negros de las favelas, quienes, según las investigadoras, son detenidos por la Policía el 30\% más a menudo que los blancos de otras áreas. En Brasil, el estereotipo de hombres negros jóvenes criminales se transmite por los medios de comunicación a través de películas y novelas que los muestran constantemente como narcotraficantes, asesinos despiadados, drogadictos o delincuentes. Esta exposición diaria de cuerpos negros realizando personajes estereotipados y racistas es una forma de violencia simbólica, que es la manera en que las relaciones de dominación pueden ser configuradas, mantenidas o restauradas (Bourdieu, 2007 [1977], p. 191). Estas imágenes ayudan a mantener el temor al cuerpo negro y se han extendido al conjunto de la sociedad.

En los Estados Unidos, también es evidente la discriminación racial en la práctica policial llamada stop and frisk [detener y registrar] usada en la vigilancia de la juventud negra (Newberr, 2017). Una breve revisión de la literatura sobre la

Hooks (2004) define la masculinidad patriarcal como el deseo de los hombres por controlar a las mujeres, niños y algunos hombres (p. 18). Para Gordon (1997), en una sociedad racista patriarcal, donde los hombres blancos son definidos como pertenecientes a la cúspide de la cadena jerárquica, los hombres negros tienen que luchar contra otros en las comunidades en busca del poder que queda para ellos en la sociedad, lo que lleva a amenazas, asesinatos y terror fraternal. 
Policía en Estados Unidos muestra que estrategias policiales proactivas también producen una serie de perjuicios para los afroamericanos en comunidades urbanas pobres. Friedman et al. (2004) encontraron que la juventud americana negra es más propensa que otros grupos raciales a reportar el abuso físico durante las redadas policiales. Las controlling images [imágenes de control] ${ }^{3}$ de hombres jóvenes negros como posibles ladrones, en las que son definidos y tratados como criminales, están profundamente arraigadas en la cultura americana (Worden, 1996). Kraska y Kappeler (1995) sugieren que los jóvenes negros pobres son más vulnerables a las prácticas abusivas de la Policía.

Otra similitud entre los dos países es la necesidad de fuertes campañas y presión pública para visualizar las muertes femeninas. En los Estados Unidos, la campaña \#SayHerName [«decir su nombre»] intenta dar visibilidad a las muertes de las mujeres negras cometidas por la Policía. Kimberlé Crenshaw, cofundador de la campaña, advierte que:

Aunque las mujeres negras son rutinariamente muertas, violadas, y golpeadas por la Policía, sus experiencias raramente están en primer plano en la comprensión popular de la brutalidad policial. Sin embargo, la inclusión de las experiencias de las mujeres negras en movimientos sociales, narrativas de medios y necesidades políticas en torno a policiamiento y brutalidad policial es fundamental para efectivamente combatir la violencia racializada del Estado para las comunidades negras y otras comunidades de color (\#SayHerName, s.f.).

En Brasil, las mujeres negras jóvenes también se ven muy afectadas por la violencia que aflige a la juventud negra, aun cuando son el 8,4\% de las víctimas de homicidio (Waiselfisz, 2014). Sus experiencias solo tienen a ganar notoriedad cuando el caso tiene refinamientos crueles o contribuye a espectacularizar el sufrimiento negro (Hartman, 1997). Un ejemplo fue la muerte de la brasileña Claudia Ferreira da Silva en marzo del 2013. Claudia era una mujer negra que vivía en una favela de la ciudad de Río y que recibió dos disparos durante una operación policial cuando salía de su casa para comprar pan para sus cuatro hijos. Después del tiroteo, la Policía la colocó en el maletero del coche, alegando que la

3 El término imágenes de control fue utilizado por la teórica Patricia Hill Collins para definir la forma en que las imágenes negativas de las mujeres negras han producido una justificación de las desigualdades de raza, género y clase. Se utilizan las imágenes de control de mammys, matriarcas y otras imágenes para caracterizar a mujeres negras en los medios y en la sociedad en modos particulares (Collins, 1991). De la misma forma opera el control de los jóvenes negros a partir de la imagen del criminal o bandido. 
estaban llevando al hospital. El maletero del vehículo policial se abrió y Claudia fue arrastrada por varias cuadras hasta que la Policía se detuvo para colocar su cuerpo de nuevo hacia adentro. La Policía no fue acusada, lo que generó la movilización de grupos organizados contra la violencia y activistas de los movimientos negros. El intento de visibilización incluyó reuniones en universidades, marchas de protesta, y se formó, a partir de la muerte de Claudia, el colectivo de negros y negras de la Facultad Nacional de Derecho de la UFRJ, que tomó el nombre de Colectivo Negro Claudia Ferreira Silva - FND / UFRJ.

Como Frank Wilderson III (2010, p. 3) afirma, «el cuerpo negro magnetiza balas de revólver». Diversos autores argumentan que la experiencia de la diáspora africana está intrínsecamente relacionada con la muerte negra (Vargas, 2010; Nascimento, 1978; Hamilton, 1995). Esta violencia estructural hace que las mujeres negras se vean directamente afectadas por las consecuencias sociales, económicas y emocionales de la violencia sobre la población negra. Cada vida perdida cala profundamente en la red de parientes y amigos del asesinado, y especialmente en las vidas de las madres, que a menudo son madres solteras o las principales proveedoras financieras de la familia. Esto provoca una enorme cantidad de sufrimiento, dolor, tristeza y desesperación, pero nos muestran su capacidad de luchar contra la estructura generadora de muerte que desmantela a sus familias a través de su maternidad preservativa, es decir, a través de la acción que intenta garantizar la existencia física de sus hijos y los hijos de la comunidad en una realidad racial y socioeconómica que atrae a los jóvenes al fetichismo del poder efímero de la delincuencia. Yo uso el concepto de fetiche de poder para describir la devoción a una autoridad imaginaria y mando de necropolítica (Mbembe, 2003) que atrae a los jóvenes a introducirse en actividades criminales, lo que acelera su encuentro con la muerte violenta.

Cuando ocurren muertes violentas como consecuencia de la acción de la Policía, especialmente si son jóvenes sin participación en el crimen, las madres muestran una fuerte reacción emocional a la violencia: ira, indignación, arrebato. La investigación etnográfica realizada entre julio de 2011 y diciembre de 2012 con veintisiete madres que tenían hijos e hijas asesinados en Río de Janeiro, así como artículos en los principales periódicos de Estados Unidos que reproducen los relatos de las madres de las víctimas de violencia policial, me ayudarán a identificar las características de lo que llamo lucha indignada.

Al examinar las experiencias y estrategias de Elizabeth Mamie Till-Mobley en Mississippi, Deize Carvalho y Márcia Jacinto en Río de Janeiro, Sybrina Fulton, en Florida y, más recientemente, Lesley McSpadden en Ferguson, vemos 
que esas mujeres tienen en común no solo el asesinato de un hijo o hija: ellas comparten una resistencia que se basa en el uso de la emoción para denunciar la violencia que se ejerce sobre sus vidas. A continuación, se destacan algunas de las características de las pedagogías de resistencia de estas madres, es decir, las formas comunes en las que estas madres negras ejercen su lucha indignada, y se enseñan unas a otras y a la sociedad a través de sus experiencias de tristeza.

Como se podrá ver a continuación, la lucha indignada es una estrategia política practicada por las madres de las víctimas de la violencia para denunciar el terror y el racismo que resultan en extrema violencia en la vida de las mujeres negras. Esta es la acción de las madres que vieron su maternidad interrumpida por acción directa del Estado, a través de la violencia de la policía o a través de un sistema judicial injusto y racista que remata ${ }^{4}$ a sus hijos y niega a las personas pobres y negras la posibilidad de investigación y el juicio eficiente. En este artículo analizamos la maternidad negra en Brasil y los Estados Unidos utilizando el concepto de lucha indignada desde una «antropología de la indignación», que usa la emoción como marco analítico para comprender cómo el racismo se incorpora estructuralmente en instituciones represoras en comunidades negras, y cómo nuestra comprensión de este fenómeno puede ayudar a mejorar nuestras metodologías de investigación activistas.

\section{INDIGNACIÓN COMO RESPUESTA AL TERROR}

Márcia Jacintho es una mujer negra moradora del Morro del Gambá en la ciudad de Río de Janeiro. Su hijo fue baleado en una acción policial fraudulenta en la comunidad en que vivían. De acuerdo con la denuncia contra los policías, después de haber matado al joven y comprobado que no formaba parte de un grupo delictivo, los policías habrían fraguado la escena del crimen y registrado la ocurrencia como si el joven hubiera portado un revólver calibre 38 y disparado, por lo que ellos respondieron a la acción del joven.

El 20 de marzo de 2012 tuvo lugar en el Tribunal de Justicia de Río de Janeiro el juicio de uno de los policías acusados del asesinato. Márcia Jacintho organizó una protesta en frente del edificio durante unas dos horas antes de entrar a la

4 Nosotros utilizamos el término re-muertos y rematar para definir la tendencia de la Policía y los medios de comunicación en Brasil y los Estados Unidos tratando de justificar la muerte de joven negro que transportan la noticia de que eran delincuentes o matones. O por la falta de interés del sistema de justicia penal para solucionar los casos. 
corte. En uno de sus discursos, mostró toda su indignación y expresó furia por la complicidad de la policía militar que obstaculizaba su lucha por la justicia. El 20 de marzo de 2012, se realizó el juicio del asesino de su hijo. En una entrevista después del juicio, ella dijo:

Si yo no hiciera lo que hice $[\ldots]$ honestamente $[\ldots]$ incluso con ese dolor que tengo hoy nada habría ocurrido. Si hoy lo hago, es para que otras madres tengan coraje. No fui solo una mujer que colocó a un niño en el mundo. Fue un terrible dolor el traer a mi hijo en el mundo. He criado a mi hijo sin tener beneficios del Estado, pero he pagado la bala que mató a mi hijo. Nosotros pagamos la bala que sacó la vida de mi niño, que tendría veinticinco años hoy [...] Ellos no saben el dolor que causaron en mi alma para el resto de mi vida. Nueve años y cinco meses después de la muerte de mi hijo, estoy aquí de nuevo. Diez años después, ¿a cuántas otras personas se mató? Las vidas de jóvenes que están allí en la comunidad no valen nada.

El discurso de Márcia es sobre «odio, indignidades, y erupciones de violencia que amenazaban a las personas negras» (Davies, 1998, p. 182). Su discurso es sobre la maternidad indignada.

Según los estudiosos dedicados a la antropología de las emociones, es imposible saber lo que otras personas están sintiendo, y solo podemos llegar a ella a través de lo que él o ella expresan verbalmente (Rosaldo, 1980; Lutz y White, 1986; Abu-Lughod, 1986; Triana, 2012). En la introducción a uno de los trabajos clásicos de la antropología de la emoción, Language and the Politics of Emotion [Lenguaje y la política de emoción], las estudiosas Lila Abu-Lughod y Catherine A. Lutz (1990: 1) sostienen que «discurso» es un término clave para este tipo de antropología, «sin la cual la emoción no puede ser adecuadamente comprendida».

La antropóloga brasileña Maria Claudia Coelho (2010) aplica el razonamiento de Abu-Lughod y Lutz al estudio de las narrativas de la violencia en parejas de clase media en Río de Janeiro cuyas casas fueron robadas, con el fin de comprender las cuestiones de género en sus intervenciones. Sin embargo, a pesar del hecho de que desarrolla una manera de poner en práctica la antropología de las emociones en Brasil, una debilidad de su análisis es el hecho de que no tiene en cuenta la manera como la raza y la clase interactúan en la formación de estos discursos. Para poder incorporarlos en el análisis es importante considerar el argumento de Toni Morrison (2010, p. 26) sobre las unspeakable things unspoken [cosas indecibles no dichas]. Morrison sugiere que «la raza sigue siendo una cosa prácticamente indescriptible». Así, para hacer visible la raza en el estudio de las emociones, es necesario considerar que el racismo es un indecible no dicho, pero sentido. 
Esto significa que no siempre somos capaces de expresar nuestros sentimientos a través del lenguaje. El sufrimiento continuo de los negros es naturalizado en la sociedad, y esa naturalización contribuye a la invisibilidad de las cuestiones que les conciernen.

La teoría del afecto defiende la importancia de considerar el «afecto» en la investigación por razones analíticas y políticas. Así, Kathleen Stewart, en Ordinary Affects [Afectos ordinarios] (2007), llama la atención sobre el modo como los «sentimientos» se generan en el diálogo con el mundo. Según ella, las motivaciones, los deseos, miedos y tensiones que dan forma al mundo vivido son co-constituidos por seres los humanos y el mundo circundante. Por ejemplo, algunas madres relatan sentir ansiedad ante la presencia de policías, mientras que otras sienten fuerte disgusto cuando oyen hablar de drogas. Otras expresan su furia cuando los medios de comunicación caracterizan a los habitantes de las favelas como potenciales criminales. Sus sentimientos se generan a través de las interacciones con los agentes de la opresión y expresan la causa de su infelicidad de mujeres negras en una sociedad racista. Sobre la base del argumento de Stewart, entiendo el afecto de las madres negras como una expresión de racismo y violencia que conduce a acciones. La antropóloga Zora Neale Hurston (s.f.) dijo una vez: «Si mantienes silencio sobre tu dolor, te van a matar y decir que te gustó».

Esta frase de Hurston ayuda a identificar la primera característica de la lucha indignada de madres de víctimas de violencia: la visibilización de la atrocidad causada por la violencia y el racismo. Mamie Till-Mobley, la madre de Emmett Till, un niño negro de catorce años de Chicago que fue asesinado en agosto de 1955 mientras visitaba a sus parientes en Mississippi, no mantuvo su sufrimiento en silencio. Después de ver los restos mutilados de su hijo, ella decidió que el mundo entero debería ver lo que asesinos racistas le habían hecho a su único hijo. Jet (1955), una revista semanal afroestadounidense publicó una foto del cuerpo de Emmett, y luego la historia se dio a conocer a la gente. En su autobiografía titulada Death of Innocence (Till-Mobley y Benson, 2003, p. 54), Mammie Till-Mobleyanaliza su elección de tener una ceremonia de cajón abierto en el funeral de su hijo. Ella dice: «[...] la gente tenía que enfrentar a mi hijo y percibir cuán torcido y distorsionado podía ser un terrible odio racial. La gente tenía que considerar todo aquello al ver el cuerpo de Emmett. La nación entera tuvo que ser testigo de ella». La indignación de Till-Mobley mostró las atrocidades producidas por la ley Jim $\mathrm{Crow}^{5}$ en la sociedad.

5 En resumen, Jim Crow se puede describir como la forma antigua de la segregación de los negros en los Estados Unidos. Involucra legislación, imágenes inhumanizadas de negros e 
Deize Carvalho en Río de Janeiro, Brasil, utilizó una estrategia similar para mostrar el legado de barbarie que la dictadura militar brasileña dejó en la estructura de las instituciones correccionales y punitivas brasileñas, como las prisiones y los centros de rehabilitación de menores. En 2008, agentes penitenciarios de la Dirección General de Actividades Socioeducativas (Degase) ${ }^{6}$ mataron al hijo de Deize, Andreu, donde se encontraba recluido. Desde la muerte de Andreu, en 2008, Deize ha luchado por refutar la versión dada por los agentes estatales sobre la muerte de su hijo. La historia contada por los agentes de seguridad del Degase dice que Andreu intentó escapar escalando una pared muy alta, cayó y se golpeó la cabeza. Sin embargo, Deize sostiene que las contusiones en el cuerpo de Andreu no se correspondían con esta historia. El daño fue tal que a Deize y su familia se les impidió vestir el cadáver para el entierro. Ella siguió un largo camino hasta conseguir autorización para la exhumación del cuerpo de su hijo, con el fin de tener una autopsia detallada que mostró las reales causas de la muerte de Andreu. Esta autorización se logró recién en marzo de 2009 y se ordenó al Instituto Médico Legal (IML) ${ }^{7}$ que realizara un nuevo informe de autopsia.

Sin embargo, el Instituto no acató la decisión, que fue reafirmada en noviembre de 2009 por otra decisión judicial. En el caso de las madres y familias de otros jóvenes desaparecidos y asesinados en circunstancias similares, el IML si acató la decisión judicial (Rede de Comunidades e Movimentos contra a Violência, 2013).

A diferencia de la ficción sobre investigadores forenses del programa Huesos de la televisión estadounidense, donde los antropólogos forenses y otros expertos trabajan juntos para encontrar la causa de la muerte y las posibles características del asesino involucrados en los huesos de las víctimas, los médicos de Río de Janeiro se han negado a proporcionar respuestas a preguntas básicas que el fiscal había hecho acerca de la muerte de Andreu. El peso de la burocracia y el compromiso de los médicos con los intereses del Estado contribuyó a la impunidad.

intensa violencia y linchamientos principalmente en el sur del país. Para más información ver Smith (2002).

$6 \quad$ La Degase es una institución vinculada con la Secretaría de Educación y responsable por la implementación de medidas sociales y educativas aplicadas por el Poder Judicial para jóvenes en conflicto con la ley.

$7 \quad$ El Instituto Médico Legal es un organismo público vinculado con la Secretaría de Estado para la Seguridad Pública. En el ámbito de la medicina legal, realiza pericia forense en cadáveres, partes del cuerpo, esqueletos completos o no, y en personas vivas, así como exámenes complementarios (laboratorios) en las áreas de patología, toxicología, química y forense, solicitados por las autoridades policiales y judiciales, necesarias para aclarar a la Policía los procedimientos judiciales y los procedimientos administrativos. 
Sin embargo, ante la necesidad de hacer público lo ocurrido con su hijo, Deize usó su red de apoyo para que varias personas fueran con ella al cementerio en el momento de la exhumación, tomar fotos y grabar conversaciones de los médicos y de los expertos forenses. Las fotos del cráneo de Andreu roto, de la mandíbula desconectada y de todas sus costillas fracturadas sirvieron como prueba de la brutalidad sufrida por él. Las fotos fueron anexadas a los documentos de investigación de la Policía, y en mayo de 2011, el Ministerio Público denunció a los seis agentes disciplinarios por asesinato y pidió su retiro del servicio (Red, 2013). Sin embargo, incluso después de casi diez años, en agosto de 2018 el proceso aún se tramita en el sistema judicial brasileño.

Saidiya Hartman (1997) hace una crítica de la pornografía del sufrimiento negro y de la exposición del cuerpo negro muerto. Sin embargo, era esencial para la resistencia de Mammie Till y Deize Carvalho que los cuerpos de sus hijos pudieran contar la historia de sus muertes. Sus cuerpos hablaron. Miles de personas pasaron por el cuerpo deformado, y los Estados Unidos nunca olvidará el horror de los linchamientos provocados por la ley Jim Crow gracias al cadáver de Emett Till. La exhumación del cuerpo de Andreu mostró que no tenía un solo hueso que no se hubiera roto en su tronco. Y con las fotos de la exhumación, Deize finalmente reunió las pruebas necesarias para presentar queja contra los seis agentes de detención que torturaron y golpearon brutalmente a su hijo de diecisiete años de edad en su primera noche en la custodia del Estado.

La segunda característica de la lucha indignada de las madres negras tiene que ver con la imposibilidad de evitar el dolor y usarlo en su estrategia política. El 18 de agosto de 2014, en una carta dirigida a la familia de Michael Brown, Sybrina Fulton, madre de Trayvon Martin, el joven negro de diecisiete años muerto a tiros por un voluntario de vigilancia de barrio en Sanford, Florida, alertó:

Para complicar aún más el dolor y la pérdida en esta tragedia está el hecho de que el asesino de su hijo está vivo, conocido, y actualmente libre. Sus propios sentimientos van a saltar de la tristeza a la ira. Incluso cuando usted no quiere pensar en ello, porque es muy difícil de soportar, se verá forzada a hacerlo simplemente al encender su televisor o responder a su teléfono celular (Fulton, 2014).

En la carta, Sybrina Fulton alerta a la familia Brown a través de su experiencia, establece una conexión con ellos a través de la tristeza que ambas familias sentían después de la muerte de sus hijos, y propone el uso de la emoción como estrategia política de conciencia de la violencia anti negra como una manera de buscar la justicia. Además, dice: 
[...] si se niegan a escucharnos, vamos a hacerlos sentirnos. Algunos van a confundir esta última afirmación como negativamente provocativa. Pero sentirnos significa sentir nuestro dolor, imaginando nuestra situación como padres de niños muertos. No vamos a ser ignoradas. Vamos a unirnos, continuar nuestras luchas por la justicia, y hacerlos recordar a nuestros hijos bajo una luz apropiada.

En la investigación realizada entre 2011 y 2013 con madres de víctimas de violencia en Río de Janeiro, aprendí a prestar atención a las expresiones de los sentimientos de las madres y a mis propios sentimientos al escuchar sus narraciones de sufrimiento y resistencia. Aprendí que no es posible ser pasiva mientras se oye y observa a las fuertes mujeres negras, pues, tal como dice Sybrina Fulton en el pasaje citado, ellas convocan nuestras emociones como parte de su política.

La tercera característica de la lucha de las madres indignadas es nombrar al opresor. En varias apariciones públicas, Deize Carvalho nombra a todas las estructuras de opresión y personas directamente involucradas en el asesinato de su hijo. Nombra no solo a los violentos agentes de policía, sino también al gobernador del estado de Río de Janeiro, al secretario de seguridad pública y a la política de seguridad de una manera general. Esto coincide con lo que apunta la intelectual negra americana Joy James (1999) en su libro Shadowboxing. El término shadowboxing se refiere al entrenamiento de boxeo y la lucha contra un oponente imaginario con el fin de entrenar. James imagina que el Estado es este oponente imaginario que está allí, pero no vemos. Y nos invita a nunca parar de luchar contra este oponente invisible en cualquier estrategia que usemos. Deize revela que sus principales estrategias de lucha contra el estado son denunciar las violaciones y alentar a otras madres que pasaron por la misma situación de muerte violenta a luchar. Ella explica en una conversación:

Eso [la violencia contra los negros y pobres] está lejos de terminar. Nosotros, de las favelas, todavía somos vistos como objetos de menor valor. Por eso es importante combatirlos, para mostrar que mi hijo era un ciudadano. Las personas de las favelas son ciudadanas también. Nuestras vidas importan. Mi experiencia puede ayudar a otras madres, porque las muertes se suceden todo el tiempo. Es más, la Policía nos mata todo tiempo.

Nombrar las razones de su indignación también forma parte de la lucha de Sybrina Futon y Lesley McSpadden. El 7 de julio de 2013, Fulton denunció el racismo en una reunión en Nueva York, una semana después de que el jurado considera a George Zimmerman no culpable de la muerte de adolescente desarmado Trayvon Martin. Ella dijo: «A veces pienso en lo que Trayvon sintió esa noche, 
y en lo que otros jóvenes como él pueden sentir mientras caminan a casa pensando en la vida, y debido a la percepción de otra persona sobre ellos, a causa del racismo, algo es incorrecto [...]» (Grossman, 2013).

En otro momento de su discurso público, Sybrina Fulton habla sobre cómo la tristeza motiva la acción de indignación. Ella afirma:

Mi hijo murió sin siquiera saber quién era su asesino, lo que es muy triste $[\ldots]$ pero no es triste hasta el punto de que solo me haga quedarse en casa y llorar sin hacer nada. Es triste hasta el punto de que me muestra, que confirma para mí que tenemos mucho trabajo por hacer $[\ldots]$ Ahora tengo un nuevo enfoque: el foco son nuestros hijos (Grossman, 2013).

Fulton usa la tristeza como una manera de convertirse en una othermother [otra madre], es decir, «compartiendo la responsabilidad de nutrir y asistir a la infancia la supervivencia de la comunidad negra» (James, 1993, p. 45). Para garantizar su supervivencia, Fulton sostiene que el sistema judicial y la ley «no funcionan para nosotros»y deben ser cambiados (Grossman, 2013). De la misma forma, la indignación de Lesley McSpadden fue evidente en la noche de la decisión del gran jurado de no acusar a Darren Wilson, el policía asesino de su hijo. De pie sobre el capó de un carro y rodeada por una multitud, McSpadden grita de dolor y rabia diciendo: «Yo viví aquí toda mi vida y nunca tuve que pasar por nada parecido a eso $[\ldots]$ ¡Ellos son unos malditos mentirosos!».

Un hecho que causó controversia esa noche en Ferguson fue que el compañero de Lesley, en un momento catártico de tristeza, gritó: «iQuemen esta ciudad!». Fue criticado por incitar a una rebelión. Esto ocurrió porque Ferguson ardió en protestas violentas e incendios después de la decisión del jurado. Sin embargo, el uso de fuego como una forma de protesta no es nuevo ni exclusivo de Estados Unidos. En Río de Janeiro, muchas veces es la única manera que los habitantes de la favela encuentran para hacer la brutalidad policial más visible. Comprender el acto de prender fuego a las cosas tiene que ver con la comprensión de las estrategias que encuentran las personas negras con rabia para denunciar o escapar de situaciones de violencia y para resistir. Sin embargo, los medios de comunicación borran las motivaciones sociales y políticas detrás del «fuego» y el acto de conciencia política y califica estos actos como mero vandalismo o instancias del crimen organizado. Un ejemplo es que todas las veces que la gente de los barrios bajos de la colina protestan en las calles de Copacabana ${ }^{8}$ o en otros barrios se la clasifica

8 Copacabana es una zona privilegiada de Río de Janeiro, donde en las calles bajas vive población en su mayoría blanca y en las colinas que rodean vive la población negra. Es el ejemplo clásico de la segregación territorial espacial. 
como problemática o como responsables en el tráfico de drogas. Manifestaciones urbanas violentas negras en ciudades de Brasil y Estados Unidos son una estrategia para denunciar el genocidio y una manifestación humana de rabia. Como dijo el abogado de la familia Brown, Benjamin Crump, esta es «emoción cruda. No los condene por ser humanos» (Stableford, 2014, párrafos 8 y 10).

¿Qué nos dicen estas reacciones sobre la investigación antropológica? ¿Qué puede la maternidad indignada enseñarles a nuestras prácticas metodológicas? ¿Cómo puede un análisis de las emociones que considere el racismo mejorar nuestras reflexiones y metodologías? Reflexionamos sobre estas cuestiones en la última sección de este artículo.

\section{POR UNA ANTROPOLOGÍA DE LA INDIGNACIÓN}

Basado en las experiencias de maternidad en geografías de muerte de Mamie Elizabeth Till-Mobley, Deize Carvalho, Márcia Jacintho, Sybrina Fulton y Lesley McSpadden, propongo una antropología de la indignación; es decir, una antropología que reconoce emociones como una expresión de la posición de una persona o grupo de personas en una estructura injusta de poder, específicamente el racismo. La antropología de la indignación reconoce cómo las personas expresan la emoción como un motor central de su lucha de resistencia y lucha colectiva y utiliza el sentimiento resultante de las interacciones con esas personas como combustible para producir materiales comprometidos. Así, al reconocerlo, se amplían las posibilidades de destacar situaciones de explotación, opresión y discriminación mientras se asegura que las personas estudiadas puedan expresarse de formas verbales y no verbales.

El diálogo con las reflexiones que incorporan críticamente varias esferas de la existencia humana en el trabajo académico me ayudó a incorporar las emociones como una herramienta analítica para denunciar el racismo. En diálogo con estudiosos reconocidos en investigación activista y antropología de las emociones, sostengo que la incorporación de la emoción en la metodología, análisis y escritura humaniza la investigación al reconocer una nueva fuente de conocimiento y posibilidades políticas. Esto prolonga el enfoque etnográfico feminista, que según Craven y Davis (2014) es «un proyecto que se compromete a documentar cómo las experiencias vividas son afectadas por el género, la raza, la clase, la sexualidad y otros aspectos de la vida de los participantes» (p. 1), tales como emociones, que pueden dotar a los resultados con la sensibilidad necesaria para abordar cuestiones específicas de la vida de las mujeres negras. 
En The Uses of Anger: Women Redefining Difference [Usos de rabia: mujeres redefiniendo la diferencia], la escritora feminista negra Audre Lorde (1984,p. 124) sostiene que «la ira es una respuesta a las actitudes racistas y a las acciones y supuestos que resultan de tales actitudes». Así, antropólogos activistas que trabajan con grupos oprimidos deben ser conscientes de la indignación, rabia y otras emociones como categorías de resistencia que deben ser usadas para entender la «intencionalidad, análisis y prácticas transformadoras de los grupos» (Gordon, 2007).

Para continuar el desafío de la producción antropológica activista de no alimentar el statu quo, es importante que los antropólogos oriundos o comprometidos con movimientos sociales y grupos marginados o que tengan un compromiso político de luchas sociales creen espacios para nuevos enfoques dentro de la academia. Es necesario hacer llegar las voces, experiencias, pensamientos y sentimientos desde los márgenes hacia el centro, pero también es preciso construir teorías del cambio social basadas en tales epistemologías. Así, como Hale (2008: 11), quien argumenta que un medio eficaz de combatir la opresión académica es «recuperar los términos, dándoles nuevos significados», resignifiquemos la rabia, el silencio, el grito y el miedo en el ámbito de la antropología de la indignación.

De acuerdo con Joy James y Edmund Gordon (2008, p. 367), para crear esos nuevos significados es necesaria la transformación de las «competencias académicas en instrumentos de pasión por el cambio social transformador y la liberación humana». Al trabajar con las emociones, los autores usan los sentimientos de esperanza, amor y deseo como herramientas motivacionales para proporcionar posibilidades contrahegemónicas para proseguir la investigación descolonizada en la arena académica.

Desarrollar una investigación indignada es un desafío no solo al hacer el trabajo de campo, sino también cuando se escribe y se está dentro de la academia en general. Como Hale (2007, p. 3) sugiere:

para las personas que se sienten directa y personalmente ligadas a experiencias más amplias de opresión y de luchas por la emancipación, las reivindicaciones de la objetividad son más aptas para sonar como maniobras de autoservicio para preservar la jerarquía y privilegio; y la idea de poner la producción académica al servicio del empoderamiento de sus propias comunidades y el bienestar es más apta para sonar como una sensata — si no una inevitable - forma de practicar su profesión.

La autoetnografía de la indignación también es muy importante y reveladora para la producción antropológica comprometida. En mi investigación, el uso de emociones apareció no solo a través de las narrativas de las madres, sino también 
a través de la forma como su indignación me afectó y me impulsó a involucrarme con sus sentimientos y acciones de indignación. Yo escribí en estado de shock como consecuencia de todas las atrocidades vistas y oídas, estaba motivada por la rabia, sufriendo, y, por lo tanto, ultrajada e indignada.

Sin embargo, y aunque defiendo una antropología indignada a servicio de la liberación negra, no sugiero perderse en la emoción debido a la participación política. Como se ve en la experiencia de las madres de víctima de violencia, la emoción puede motivar cuidadosa y deliberadamente la práctica política y no es, como se asume a menudo, que la emoción produce impulsividad. Además, al escribir una etnografía, antropólogos y antropólogas deberían abrazar la indignación como una fuente de fuerza para buscar métodos científicos y argumentación intelectual con el fin de producir material que pueda contribuir a la lucha de aquellos que fueron socios en la investigación.

En este punto es fructífero retomar el análisis de Toni Morrison (2000) sobre la raza como cosa tácita indecible que nos ayuda a comprender que las madres negras no siempre eran capaces de expresar sus sentimientos a través del lenguaje, y que la naturalización de las muertes de negros en la sociedad contribuye a la invisibilidad de los problemas que los afectan. Cuando se realiza por antropólogos identificados y alineados con un grupo organizado en lucha, la investigación puede revelar las estructuras emocionales que se dan entre violencia y racismo y proporciona nuevos análisis. Esto significa que, por ejemplo, antropólogos activistas negros que realizan trabajo de campo en casa (Rodríguez, 2001) están en una posición privilegiada para comprender los procesos de racismo y las formas en que está enmascarado en la sociedad y sentido por aquellos que sufren con eso.

En conclusión, la fuerza de las madres negras viene de la indignación surgida después de sufrir una pérdida, y su activismo en busca de la justicia abre caminos de visibilidad y movilización en torno a la muerte prematura y evitable negra (masculina y femenina). Sus experiencias sugieren que el sufrimiento causado por línea materna interrumpido por la violencia y la lucha por hacer frente al terror en sus vidas las hacen un grupo político distinto. Inspirada en su resistencia, una antropología de la indignación puede contribuir a sus luchas y también al llamado de la antropóloga Leith Mullings (2013):

Aquellos de nosotros que investigan raza, racismo y desigualdad debemos seguir citando el racismo sin endulzarlo; para analizar las formas en que el 
racismo es mantenido y producido dentro y fuera de nuestra disciplina, sin apuntar abiertamente a sus víctimas; y utilizar las herramientas de la antropología para identificar las relaciones sociales subyacentes y los funcionamientos informales de los proyectos racistas. Lo más importante: necesitamos interrogar las nuevas formas ocultas de racismo estructural y deconstruir, en el mejor sentido de la palabra, las formas por las cuales el racismo se expresa en la edad de «daltonismo post-racial». De esta forma, hacemos nuestro mejor esfuerzo para honrar memoria de aquellos - como Trayvon Martin, Andreu, Hanry y Mike Brown-, que pagaron el precio final para el racismo.

Por lo tanto, es importante que en nuestras investigaciones y escrituras académicas nunca dejemos de visibilizar las atrocidades del racismo, de usar el dolor y las emociones como herramienta política y analítica ni de nombrar a los opresores.

\section{REFERENCIAS BIBLIOGRÁFICAS}

\#SayHerName (s.f.). \#SayHerName: Resisting Police Brutality against Black Women. Disponible en http://www.aapf.org/sayhernamereport/

Abu-Lughod, Lila (1986). Veiled Sentiments. Oakland, CA: University of California Press.

Bourdieu, Pierre (2007[1977]). Outline of a Theory of Practice. Nueva York: Cambridge University Press.

Carvalho. D. (2012). Judicial Hearing. Fieldwork notes.

Cerqueira, Daniel et al. (2018) Atlas da Violência 2018. Disponible en https://www.ipea. gov.br/portal/images/stories/PDFs/relatorio_institucional/180604_atlas_da_violencia_2018.pdf

Coelho, Maria Claudia (2010). Narratives of violence: the micropolitical dimension of emotions. Mana, 5.

Collins, Patricia Hill (1991). Black Feminist Thought: Knowledge, Consciousness and the Politics of Empowerment. Routledge.

Craven Christa y Dána-Ain Davis (2014). Feminist Activist Ethnography: Counterpoints to Neoliberalism in North America. Nueva York, NY: Lexington Books.

Dicionário Aurélio (n.d). Ultraje. https://dicionariodoaurelio.com/ultraje

Folha de S. Paulo (2014). Mulher arrastada por carro da PM foi morta por tiro, aponta laudo. Cotidiano. Recuperado el 29 de junio de 2014, de http://www1.folha. uol.com.br/cotidiano/2014/03/1427471-mulher-arrastada-por-carro-da-pm-foimorta-por-tiro-aponta-laudo.shtml 
Friedman, W., A. J. Lurigio, R. G. Greenleaf y S. Albertson (2004). Encounters between Police and Youth: Social Costs of Disrespect. Journal of Crime and Justice, 27, $1-25$.

Fulton, Sybrina (2014). Trayvon Martin’s Mom: «If They Refuse to Hear Us, We Will Make Them Feel Us» Opinion - Justice - TIME. Recuperado de http://time. com/3136685/travyon-sybrina-fulton-ferguson/

G1. 2018. Cresce número de pessoas mortas pela polícia no Brasil; assassinatos de policiais caem Monitor da Violência. Disponible en https://g1.globo.com/ monitor-da-violencia/noticia/cresce-numero-de-pessoas-mortas-pela-policia-nobrasil-assassinatos-de-policiais-caem.ghtml

Geledes (2014). Tereza de Benguela, uma heroina negra. Disponible en https://www. geledes.org.br/tereza-de-benguela-uma-heroina-negra/

Gordon, Edmund T. (1997a). Anthropology and Liberation. En Faye Venetia Harrison (ed.), Association of Black Anthropologists. Arlington, VA: Association of Black Anthropologists.

Gordon, Edmund T. (1997b). Cultural Politics of Black Masculinity. Transforming Anthropology, 6(1-2), 36-53. https://anthrosource.onlinelibrary.wiley.com/doi/ abs/10.1525/tran.1997.6.1-2.36

Gordon, Edmund T. (2007). The Austin School Manifesto: An Approach to the Black or African Diaspora. Cultural Dynamics, 19(1), 93-97. https://journals.sagepub. com/doi/10.1177/0921374007077280

Governo do Rio de Janeiro (s.f.). Instituto Médico Legal Afrânio Peixoto. Recuperado el 15 de abril de 2015, de http://www.delegacialegal.rj.gov.br/IML.asp

Grossman, L. (2013). Sybrina Fulton FULL Speech Trayvon Martin Rally NYC 7/20/13. Recuperado el 31 de marzo de 2015, de https://www.youtube.com/ watch? $=$ = $0 \mathrm{MeBp} 7910$

Hale, Charles R. (2001). What Is Activist Research. SSRC Newsletter, 2(1-2). Disponible en http://www.cc.utexas.edu/cola/depts/anthropology/_files/PDF/Hale.pdf

Hale, Charles R. (2008). Engaging Contradictions: Theory, Politics, and Methods of Activist Scholarship. Berkeley, CA: University of California Press.

Hamilton, Ruth Simms (1995). Conceptualizing the African Diaspora. En Carlos Moore, Tanya R. Sanders y Shawna Moore (eds.), African Presence in The Americas (pp. 393-410). Trenton, NJ: Africa World Press.

Hartman, Saidiya (1997). Scenes of Subjection: Terror, Slavery, and Self-Making in Nineteenth Century America. Nueva York, NY: Oxford University Press.

Hooks, Bell (2001). Healing: Redemptive Love. In All About Love: New Visions. Nueva York, NY: Harper Perennial. 
Hooks, Bell (2004). The will to change: men, masculinity, and love. Nueva York, NY: Atria Books.

IPEA (2018). Atlas da Violência. Disponible en http://www.ipea.gov.br/portal/index. php?option $=$ com_content\&view $=$ article\&id=33410\&Itemid $=432$

James, J. (1999). Shadowboxing: Representations of Black Feminist Politics. Nueva York: St. Martin's Press. https://doi.org/10.1007/978-1-137-06751-7

James, Joy y Edmund T. Gordon (2008). Afterword: Activist Scholarship or Radical Subjects? En Charles R. Hale (ed.), Engaging Contradictions: Theory, Politics, and Methods of Activist Scholarship. California: University of California Press.

James, Stanlie M. (1993). Mothering: A Possible Black Feminist Link to Social Transformation? En Stanlie M. James y Abena P. A. Busia (eds.), Theorizing Black Feminisms: The Visionary Pragmatism of Black Women (pp. 44-54). Nueva York, NY: Routledge.

Jet Magazine (Sep 15, 1955). Disponible en https://books.google.co.uk/books?id=57E DAAAAMBAJ\&printsec $=$ frontcover\&redir_esc $=\mathrm{y} \# \mathrm{v}=$ onepage\&q\&f$=$ false

Kraska, Peter y Victor Kappeler (1995). To Serve and Pursue: Exploring Police Sexual Violence against Women. Justice Quarterly - JUSTICE Q, 12, 85-111.

Lorde, Audre (1984). The Uses of Anger: Women Responding to Racism. En Sister Outsider: Essays \& Speeches by Audre Lorde (pp. 124-133). Berkeley: The Crossing Press Feminist Series.

Lowinsky, Naomi Ruth (1992). The Motherline: Every Women's Journey to Find Her Female Roots. Los Angeles, CA: Jeremy P. Tarcher.

Lowry, Beverly (2008). Harriet Tubman: Imagining a Life. Nueva York: Anchor Books.

Lutz, Catherine y Geoffrey White (1986). The Anthropology of Emotions. Annual Review of Anthropology, 15, 405-436. https://doi.org/10.1146/annurev. an.15.100186.002201

Mbembe, Achille (2003). Necropolitics. Public Culture. 15(1), 11-40. https://doi. org/10.1215/08992363-15-1-11

Michaelis (s.f.). Ultraje. https://michaelis.uol.com.br/moderno-portugues/busca/portugues-brasileiro/ultraje/

Morrison, Toni (2000). Unspeakable Things Unspoken: The Afro-American Presence in American Literature. En Joy James y T. Denean Sharpley-Whiting (eds.), The Black Feminist Reader (pp. 24-56). Malden, MA: Blackwell.

Mullings, Leith (2013). Trayvon Martin, Race and Anthropology. Anthropology News. http://www.anthropology-news.org/index.php/2013/07/19/trayvon-martin-raceand-anthropology/\#sthash.CJaOgf7X.dpuf 
Nascimento, A. (1978). O Genocídio do Negro Brasileiro: Processo de um Racismo Mascarado. Rio de Janeiro: Paz e Terra.

O'Reilly, A. (2004). Toni Morrison and Motherhood: A Politics of the Heart. Albany, NY: State University of New York Press.

Ramos, Silvia y Leonarda Massumeci (2005). Elemento Suspeito: Abordagem Policial e Discriminação na Cidade do Rio de Janeiro. Rio de Janeiro: Civilização Brasileira.

Rede de Comunidades e Movimentos contra a Violência (2013). Exigimos Justiça para Andreu! Que o Judiciário cumpra sua função! Rede Contra a Violência - Atividades. Recuperado el 16 de mayo de 2014, de http://www.redecontraviolencia. org/Atividades/920.html

Rodriguez, Cheryl (2001). A Homegirl Goes Home: Black Feminism and the Lure of Native Anthropology. En Irma McClaurin (ed.), Black Feminist Anthropology: Theory, Politics, Praxis and Poetics (pp. 233-258). New Brunswick, NJ: Rutgers University Press.

Rosaldo, Michelle (1980). Knowledge and Passion: Ilongot Notions of Self and Social Life. Cambridge: Cambridge University Press. https://doi.org/10.1017/ CBO9780511621833

Sakala, Leah (2014). Breaking Down Mass Incarceration in the 2010 Census: Stateby-State Incarceration Rates by Race/Ethnicity. Disponible en http://www. prisonpolicy.org/reports/rates.html in September $7^{\text {th }}, 2016$.

Smith, J. Douglas (2002). Managing White Supremacy: Race, Politics, and Citizenship in Jim Crow Virginia. Chapel Hill y Londres: The University of North Carolina Press.

Stableford, Dylan (2014). «Burn this b---- down!» Michael Brown's stepfather criticized for reaction to grand jury decision - Yahoo News. Retrieved March 31, 2015, from http://news.yahoo.com/michael-brown-stepfather-burn-this-downferguson-video-182317962.html

Stewart, Kathleen (2007). Ordinary Affects. Durham, NC: Duke University Press. https://doi.org/10.1215/9780822390404

Till-Mobley, Mamie y Christopher Benson (2003). Death of Innocence: The Story of the Hate Crime that Changed America. Nueva York, NY: Random House.

Triana, C. C. (2012). ¿Investigar las emociones? Antecedentes, retos y perspectivas. En Myriam Jimeno, Sandra Liliana Murillo y Marco Julián Martínez (eds.), Etnografias contemporáneas - Trabajo de campo. Bogotá: Universidad Nacional de Colombia.

Vargas, João Costa y Jaime Amparo Alves (2010). Geographies of death: an intersectional analysis of police lethality and the racialized regimes of citizenship in São Paulo. Ethnic and Racial Studies, 33(4), 611-636. https://doi. org/10.1080/01419870903325636 
Vargas, J. C. y J. Alves (2009). Geographies of death: an intersectional analysis of police lethality and the racialized regimes of citizenship in São Paulo. Ethnic and Racial Studies, 33(4), 1-26.

Vargas, João H. Costa (2010). Never Meant to Survive: Genocide and Utopias in Black Diaspora Communities. Lanhan, MD: Rowman \& Littlefield Publishers, Inc.

Velasco, Reis (2007). Cresce número de pessoas mortas pela polícia no Brasil; assassinatos de policiais caem. Monitor da Violência. G1 10/05/2018. https://g1.globo. com/monitor-da-violencia/noticia/cresce-numero-de-pessoas-mortas-pela-policia-no-brasil-assassinatos-de-policiais-caem.ghtml

Waiselfisz, J. J. (2014). Mapa da Violência 2014 - Os Jovens do Brasil. Disponible en http://www.mapadaviolencia.org.br/pdf2014/Mapa2014_JovensBrasil_Preliminar.pdf

Waiselfisz, J.J. (2016). Mapa da Violência 2016 - Homicídios por Arma de Fogo. Disponible en http://www.mapadaviolencia.org.br/pdf2016/Mapa2016_armas_web.pdf

Worden, William (1996). Children and Grief: When a Parent Dies. Nueva York, NY: Guilford. 